Volume 8, No.5, September - October 2019

International Journal of Advanced Trends in Computer Science and Engineering

Available Online at http://www.warse.org/IJATCSE/static/pdf/file/ijatcse65852019.pdf

https://doi.org/10.30534/ijatcse/2019/65852019

\title{
Internet marketing metrics visualization methodology for related search queries
}

\author{
Murad Omarov', Tatyana Tikhaya ${ }^{2, *}$, Vyacheslav Lyashenko ${ }^{3}$ \\ ${ }^{1}$ Department of Natural Science, Kharkiv National University of RadioElectronics, Ukraine, \\ murad.omarov@nure.ua \\ ${ }^{2}$ Department of Natural Science, Kharkiv National University of RadioElectronics, Ukraine, \\ tetiana.tykha@nure.ua \\ ${ }^{3}$ Department of Informatics, Kharkiv National University of RadioElectronics, Ukraine, \\ lyashenko.vyacheslav@gmail.com
}

\begin{abstract}
A generalization of various metrics and approaches for the disclosure of assessments of Internet marketing is given. A wavelet analysis technique is proposed for disclosing Internet marketing metrics in the case of using related search queries. Wavelet coherence is selected to understand the ideology of using wavelet analysis techniques to investigate Internet marketing metrics. The possibility of a comparative analysis for related search queries is shown. The possibility of visual analysis of Internet marketing metrics using wavelet analysis technique was noted. Specific examples of the use of coherence wavelet for analyzing Internet marketing on specific queries are given.
\end{abstract}

Key words: Wavelet coherence, Internet Marketing, Internet metric, visualization, search query.

\section{INTRODUCTION}

Internet marketing is one of the modern tools for conducting activities of various business entities. At the same time, Internet marketing is an information tool that allows you to conduct a number of different studies [1]. Such works are aimed at studying the needs of potential buyers and the possibilities of selling goods by manufacturers using modern means of communication.

In a traditional view, Internet marketing allows you to classify products in accordance with their relevance, characteristic properties and behavior of potential buyers. Therefore, information systems play a significant role in Internet marketing. These systems are able to provide communication between different groups of people, taking into account their interests and preferences [2], [3].

To implement the basic functions of Internet marketing in information systems, it is important to know a certain set of indicators that gives an idea of the preferences of customers, the demand for certain products. This requirement is due to the fact that the main task of Internet marketing is to ensure the search for various goods and services, taking into account the needs of customers and the costs of manufacturers of these goods and services.

At the same time, for the convenience of perceiving a variety of information about Internet marketing processes and the timely adoption of appropriate decisions, it is advisable to have some system of its visualization. It is on these issues that the attention is focused in this work.

\section{MATERIALS AND METHODS}

\subsection{Brief Literature Review}

Modern Internet marketing systems allow you to generate various indicators, among which, as a rule, they stand out: the number of visits to certain sites, the most used phrases that are used in search engines, the time spent on searching for the necessary information [1]. Based on this, various authors and developers choose a specific system of indicators of Internet marketing. Such a system of indicators is used in making decisions for further maintenance of the functioning system of the Internet marketing system.

For example, S. Kerai and A. Saleh [4], A. P. D. Gama [5] consider a balanced scorecard for Internet marketing. consider a balanced scorecard for Internet marketing. Among such indicators are such metrics of Internet marketing as the ratio of the costs of finding information to the income from Internet marketing, the ratio of costs and income within certain areas of Internet marketing. At the same time, to analyze such indicators, the authors use methods of descriptive and computational statistics, which are combined with the basic principles of the ideology of a balanced scorecard (BSC) [6]. Also, for the analysis of such indicators and their visualization, various table interfaces, charts, graphs are used. 
A study by J. Jarvinen and $\mathrm{H}$. Karjaluoto presents an advanced web analytics system to measure the effectiveness of Internet marketing [7]. Such a system includes both the absolute values of site traffic indicators by time and types of requests, as well as their weighted values that are reduced to search costs and revenues from such searches.

A similarly broad set of metrics for studying the effectiveness of Internet marketing was considered in the work of R. E. Bucklin, O. J. Rutz, M. Trusov [8]. Moreover, the authors give a comparative description of the metrics under consideration. However, the analysis of such metrics is not considered widely enough.

At the same time, in a number of works, special attention is paid to the costs of one click in the form of the ratio of received income (costs made) to the number of clicks relative to a certain direction of Internet marketing [9], [10]. Descriptive statistics are mainly used to analyze the obtained Internet marketing metrics in such studies.

For the analysis of Internet marketing indicators, they also use the theory of neural networks, the theory of factor analysis, and the theory of optimization [11]-[13].

At the same time, it should be borne in mind that almost all Internet metrics are based on a generalization of click dynamics relative to the search for a specific object or request. Therefore, most studies of Internet marketing metrics take as the basis precisely the dynamics of clicks over a certain period of time. Examples include studies by N. Misirlis and M. Vlachopoulou [14], S. Ainin, F. Parveen, S. Moghavvemi, N. I. Jaafar, N. L. Mohd Shuib [11], R. Saini [15], D. M. Hanssens and K. H. Pauwels [16], E. Pogorelova, I. Yakhneeva, A. Agafonova, and A. Prokubovskaya [17]. Based on this, we will also use the number of clicks in the context of certain search queries for Internet marketing in our study as an indicator of Internet marketing.

One of the key issues in the processing of statistics is the use of modern methods of processing them, which allow to clearly show trends not only in the formation of such data, but also to determine the relationship between the relevant aggregate characteristics of Internet marketing. However, the approaches outlined above for determining the estimation of Internet marketing do not sufficiently take into account the possible manifestations of influences in terms of finding related products and services and related queries. Also lacking is the visualization component of relevant analysis, which provides additional information for decision making. The disclosure of this question determines the main purpose of this study.

\subsection{Wavelet Ideology as a Tool for Analysis and Visualization of Internet Marketing Metrics}

To conduct further analysis in order to generalize the main goal of the study of this work, we will use the ideology of wavelets. This choice of tool for analyzing Internet marketing metrics is due to the fact that wavelet analysis allows the analysis of various data sets, which are presented in the form of time series [18], [19].

Among the wavelet analysis tools, the so-called wavelet coherence attracts particular attention [20], [21]. At the same time the mutual dynamics of two-time series is analyzed. Thus, the use of the coherence wavelet allows to analyze the consistency and balance of the determined dynamics from the studied data. The basis for the implementation of the coherence wavelet is the analysis of cross-references between the time series of the data being investigated. That is, as a result, we obtain a matrix of local correlations of two-time series, which determines the possibility of visualizing the effects in the mutual dynamics for the studied series.

To implement the coherence wavelet, a formalized model is used as an analysis tool wavelet coherence as the squared absolute value of the smoothed cross wavelet spectra $\mathrm{W}_{\mathrm{xy}}(\mathrm{f}, \mathrm{q})$ for different time series $\mathrm{f}$ and $\mathrm{q},(\mathrm{x}$ - first variable and $\mathrm{y}$ second variable of the data time series. Usually, $\mathrm{x}$ is a location parameter, $\mathrm{y}$ is a scale parameter, determined by maternal wavelet, normalized by the product of the smoothed individual wavelet power spectra of each series [20], [21]:

$$
R^{2}(f, q)=\frac{\left|Q\left(q^{-1} W_{x y}(f, q)\right)\right|}{Q\left(q^{-1}\left|W_{x}(f, q)\right|^{2}\right) Q\left(q^{-1} \mid W_{y}\left(f,\left.q\right|^{2}\right)\right.}
$$

where $\mathrm{Q}-$ is a smoothing operator.

Morlet wavelet is a complex wavelet with a good time-frequency localization is used as the mother wavelet [20], [21].

The squared wavelet coherency coefficient is in the range $0 \leq \mathrm{R}^{2}(\mathrm{u}, \mathrm{s}) \leq 1$, values close to zero indicates weak correlation, while values close to one are evidence of strong correlation.

Then the general algorithm for analyzing Internet marketing metrics is:

in choosing a specific query or search object for internet marketing;

in choosing the time interval on which the selected request or search object for Internet marketing will be analyzed;

calculating Internet coherence for the selected data;

generalization of the results. 


\subsection{Data for the Analysis}

To conduct an appropriate analysis, we consider the following query to evaluate the conduct of strategies in Internet marketing - "tablet computer". We will consider data from the site https://trends.google.com.ua. At the same time, we are considering this request within one country of Ukraine The data on this site reveals the interest of buyers in purchasing certain products in accordance with a specific request. In this case, this is a "tablet computer" request. As a metric for the selected query, you can consider the so-called dynamics of the query's popularity over a period of time. That is, for each defined date in the selected time interval, the relevant popularity of the query is determined by a certain level of interest in that query. In particular, 100 points is the highest level of interest, 50 points is the level of interest (and therefore the availability of queries) is twice less than the level of 100 points, 0 points is the lack of interest (in other words, there are no queries).

Figure 1 shows the corresponding dynamics of interest levels on the request of "tablet computer" in the whole of Ukraine for the next 90 days starting from 11.07.2019 (in total we have 91 values).

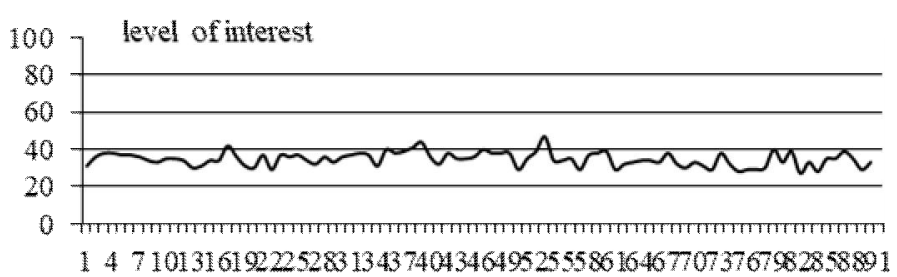

time

tablet computer

Figure 1: Dynamics of interest level on the request "tablet computer"

In accordance with Figure 1, we can see how the interest in the query "computer tablet" changes during the studied period of time. Then the goal of our consideration from the point of view of Internet marketing is to consider the influence of other similar requests on our request "computer tablet". From the point of view of Internet marketing, this question allows us to determine the limits of adjusting our behavior for the further conduct of Internet marketing in terms of the possible impact of one request on another, and therefore the corresponding flow of potential customers between different types of goods.

Therefore, we also consider the dynamics of the following queries "laptop" and "desktop computer".

Figure 2 shows the corresponding dynamics of interest levels on demand for "laptop" in the whole of Ukraine over the next 90 days, starting from 11.07.2019 (we have 91 values in general).
Figure 3 shows the corresponding dynamics of interest levels on the request of "desktop computer" in the whole of Ukraine for the next 90 days from 11.07.2019 (in total we have 91 values).

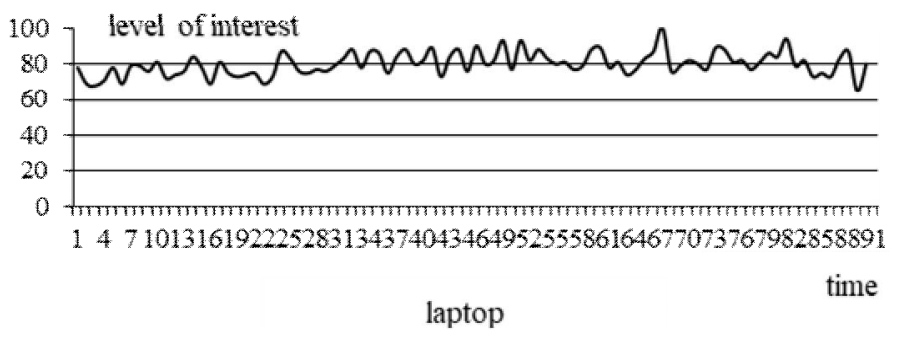

Figure 2: Dynamics of interest on laptop

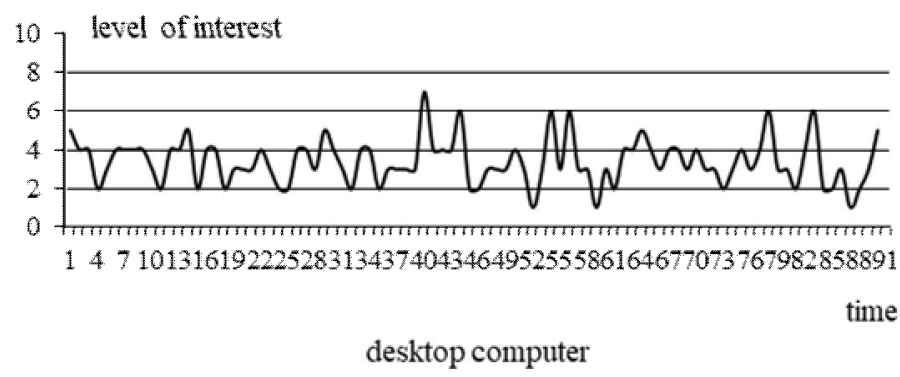

Figure 3: Dynamics of level of interest on the request of "desktop computer"

We see that the dynamics of interest for each request is different. Therefore, the question of studying the influence of individual requests on each other is relevant, especially if these requests are related.

\section{RESULTS AND DISCUSSION}

Figure 4 shows the wavelet coherence values for the requests "tablet computer" and "laptop".

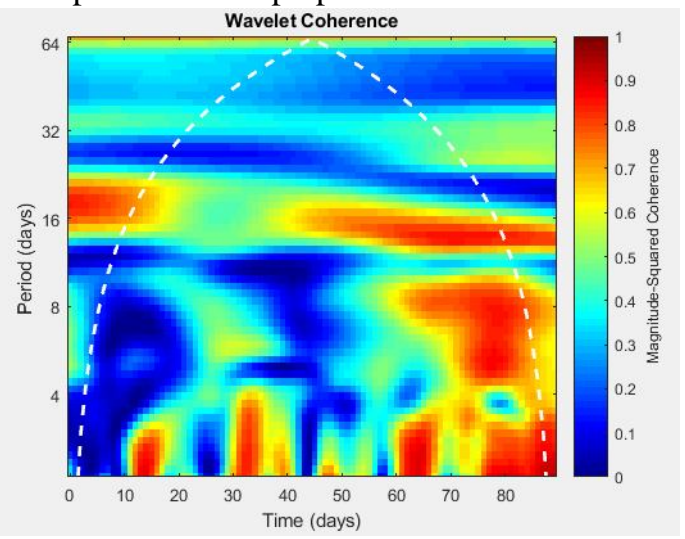

Figure 4: Coherence wavelet values for queries "tablet computer" and "laptop"."

The abscissa axis (as in Figure 4 and further for the second figures) shows a time scale that corresponds to the sequence of the analyzed data based on the selected time period. This sequence coincides with the selected time periods according (to Figure 1 - Figure 3). 
The ordinate axis (as in Figure 4 and further for the second figures) gives a weighted characteristic of the analyzed data series in the frequency space of their measurement by the results of the grouped time periods according to the total time interval. That is, this characteristic defines certain successive steps taken to determine the individual values of wavelet coherence. In other words, this is the depth of the correspondence in time between the analyzed data series.

The dashed line as in Figure 4 (and further for the second figures) in the form of an inverted parabola is the confidence line of the calculations obtained. In the middle of such parabola, the accuracy of the obtained calculations is $0.95 \%$. These calculations are based on the Monte Carlo method [20], [21].

A column as a scale for the wavelet coherence mappings is also shown along the figure. Separate areas are the localization of the manifestations of homogeneities or inhomogeneities in the individual time series studied according to their importance. In general, each point of the wavelet mapping of the studied time series is their wavelet coherence values, which are calculated by the wavelet transform.

Analyzing the data of Figure 4 in a comparative aspect with the data of Figure 1 and Figure 2, we can conclude that despite the significant interest of potential buyers in the query "laptop", this query is not dominant relative to the query "computer tablet". This conclusion is characteristic of the initial time intervals from the analyzed time period. At the same time, at the end of the analyzed time period, one can see the prevailing influence between the requests "computer tablet" and "laptop". Thus, we can talk about the presence of a seasonal factor in the conduct of Internet marketing activities in the context of such commodity items as "computer tablet" and "laptop". Figure 4 helps to determine this seasonal factor.

Figure 5 shows the values of the wavelet coherence for the requests "computer tablet" and "desktop computer".

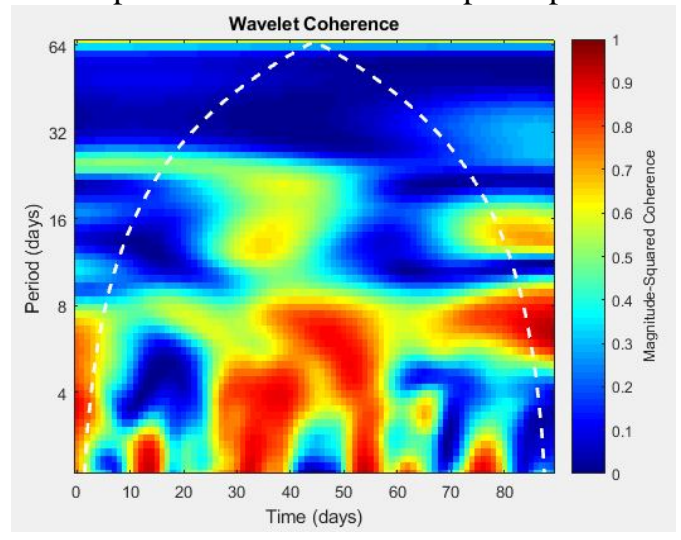

Figure 5: Coherence wavelet values for queries "tablet computer" and "desktop computer"
An analysis of the data as in Figure 5 also indicates a seasonal effect between the requests "computer tablet" and "desktop computer". Moreover, the seasonality of such an effect is different, not the same as for data as in Figure 4.

Figure 6 shows the values of the wavelet coherence for the queries "desktop computer" and "laptop".

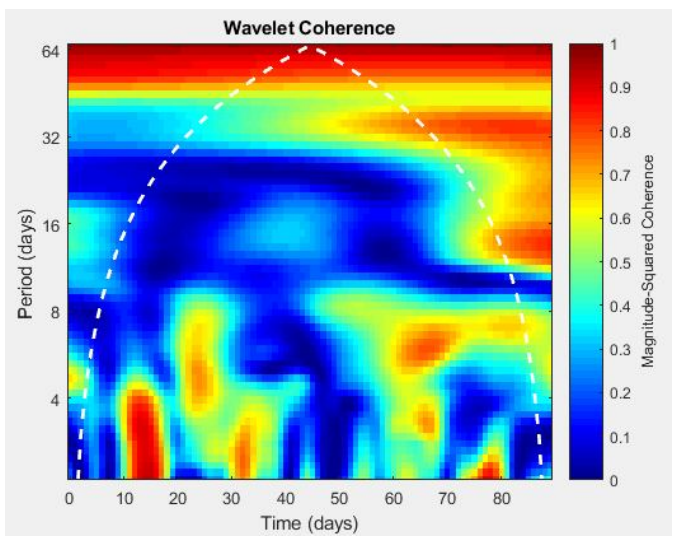

Figure 6: The values of the wavelet coherence for queries "desktop computer" and "laptop".

From the data as in Figure 6, we see the least impact between the requests "desktop computer" and "laptop". Therefore, we see that, when developing a strategy for conducting the appropriate marketing direction, it is necessary to take into account the seasonality of influence between the analyzed related search queries. At the same time, in this process it is necessary to take into account the level of interest within each search query.

\section{CONCLUSION}

The work considers the feasibility and the possibility of using the ideology of wavelets to study the conduct of Internet marketing, using its main performance metrics.

The proposed approach allows a qualitative analysis of Internet marketing in the context of related search queries. This is important for making appropriate decisions and minimizing the costs of Internet marketing.

The apparatus of wavelet coherence is considered as a tool for analyzing Internet marketing activities. The expediency of such introduction of the wavelet analysis technique is proved. Such expediency is determined by the ability to conduct a thorough analysis in the context of individual requests, which has its own logical explanation for determining the directions of Internet marketing for the selected queries. This approach also allows you to visualize the process of analysis of metrics for Internet marketing.

The results of the application of the wavelet analysis technique for the study of Internet marketing metrics in the context of click dynamics for three related competitive searches. 


\section{REFERENCES}

1. M. Omarov, T. Tikhaya, V. Lyashenko. Internet marketing technologies in civil engineering. International Journal of Civil Engineering and Technology, Vol. 9, pp. 1233-1240, July 2018.

2. D. Rani, N. S. Gill. Lightweight Security Protocols for Internet of Things: A Review. International Journal of Advanced Trends in Computer Science and Engineering, Vol. 8, no. 3, pp. 707-719, 2019.

DOI: $10.30534 /$ ijatcse/2019/58832019

3. K. Suresh, P. Reddy, P. Pushkal. Smart Home Services Using Cloud and Internet of Things. International Journal of Advanced Trends in Computer Science and Engineering, Vol. 8, no. 4, pp. 1560-1567, 2019.

DOI: $10.30534 /$ ijatcse/2019/79842019

4. S. Kerai, A. Saleh. Applying the Balanced Scorecard to Improve Student Satisfaction, Market Share and Profitability. The Applied Management Review, Vol. 1, pp. 27-38, 2017.

5. A. P. D. Gama. A balanced scorecard for marketing. International Journal of Business Performance Management, Vol. 18, no. 4, pp. 476-494, 2017. DOI:10.1504/IJBPM.2017.087116

6. S. Park, H. Lee, S. W. Chae. Rethinking balanced scorecard (BSC) measures: formative versus reflective measurement models. International Journal of Productivity and Performance Management, Vol. 66, no. 1, pp. 92-110, 2017.

DOI:10.1108/IJPPM-08-2015-0109

7. J. Järvinen, H. Karjaluoto. The use of Web analytics for digital marketing performance measurement. Industrial Marketing Management, Vol. 50, pp. 117-127, 2015.

DOI: 10.1016/j.indmarman.2015.04.009

8. R. E. Bucklin, O. J. Rutz, M Trusov. Metrics for the new internet marketing communications mix. Review of Marketing Research, Vol. 1, pp. 195-212, 2017.

9. Y. Y. K. Chen, Y. L. Jaw, B. L. Wu. Effect of digital transformation on organizational performance of SMEs: Evidence from the Taiwanese textile industry's web portal. Internet Research, Vol. 26, no. 1, pp, 186-212, 2016.

DOI:10.1108/IntR-12-2013-0265

10. Z. Yang, Y. Shi, B. Wang. Search engine marketing, financing ability and firm performance in E-commerce. Procedia Computer Science, Vol. 55, pp. 1106-1112, 2015.

DOI: 10.1016/j.procs.2015.07.078

11. S. Ainin, F. Parveen, S. Moghavvemi, N. I. Jaafar, N. L. Mohd Shuib. Factors influencing the use of social media by SMEs and its performance outcomes. Industrial Management \& Data Systems, Vol. 115, no. 3, pp. 570-588, 2015.

DOI:10.1108/IMDS-07-2014-0205
12. P. Farris, N. Bendle, P. Pfeifer, D. Reibstein. Marketing metrics: The manager's guide to measuring marketing performance. FT Press, 2015.

13. P. Phillips, K. Zigan, M. M. S. Silva, R. Schegg. The interactive effects of online reviews on the determinants of Swiss hotel performance: A neural network analysis. Tourism Management, Vol. 50, pp. 130-141, 2015. DOI:10.1016/j.tourman.2015.01.028

14. N. Misirlis, M. Vlachopoulou. Social media metrics and analytics in marketing-S3M: A mapping literature review. International Journal of Information Management, Vol. 38, no. 1, pp. 270-27, 2018. DOI:10.1016/ijinfomgt.2017.10.005

15. R. Saini. Digital marketing. International Journal in Management \& Social Science, Vol. 5, no 1, pp. 239-240, 2017.

16. D. M. Hanssens, K. H. Pauwels. Demonstrating the value of marketing. Journal of Marketing, Vol. 80, no. 6, pp. 173-190, 2016. DOI: $10.1509 / \mathrm{jm} .15 .0417$

17. E. Pogorelova, I. Yakhneeva, A. Agafonova, A. Prokubovskaya. Marketing Mix for E-commerce. International journal of environmental \& science education, Vol. 11, no. 14, pp. 6744-6759, 2016.

18. M. Dadkhah, V. V. Lyashenko, Z. V Deineko, S. Shamshirband, M. D. Jazi. Methodology of wavelet analysis in research of dynamics of phishing attacks. International Journal of Advanced Intelligence Paradigms, Vol. 12, no. 3-4, 220-238, 2019. DOI:10.1504/IJAIP.2019.098561

19. V. Lyashenko, O. Kobylin, M. Minenko, Tools for Investigating the Phishing Attacks Dynamics. In 2018 International Scientific-Practical Conference Problems of Infocommunications. Science and Technology (PIC $S \& T)$, pp. 43-46, 2018. DOI:10.1109/ INFOCOMMST.2018.8632100

20. C. Torrence, P. J. Webster. Interdecadal changes in the ENSO-monsoon system. Journal of Climate, Vol. 12, no. 8, pp. 2679-2690, 1999.

21. A. Grinsted, J. C. Moore, S. Jevrejeva. Application of the cross wavelet transform and wavelet coherence to geophysical time series. Nonlinear processes in geophysics, Vol. 11, no. 5/6, pp. 561-566, 2004. 